\title{
A CROSS-SECTIONAL STUDY OF PREVALENCE OF GASTRIC UPSET AND LOW BACK PAIN IN COMPUTER OPERATORS
}

KEY WORDS: Computer operators, Questionnaire, Muzaffarpur

\section{Arbind Kumar Sinha \\ Kamala Kanta Mishra*}

Associate Professor,Department of Physiology,Sri Krishna Medical College, Muzaffarpur.

\section{Postgraduate Student, Department of Physiology, Sri Krishna Medical} College, Muzaffarpur. *Corresponding Author

Background \& Objective: - It has been seen that computer operators work continuously in sitting posture. This leads to low back pain and various gastric problems like acidity, constipation, irregular bowel habits etc. This study aims at finding out the prevalence of these symptoms in computer operators. Methods: - 92 subjects were selected randomly from SKMCH, Newspaper offices, Banks and local markets of Muzaffarpur. A study was conducted with the help of predesigned Questionnaire from October-2019 to February-2020. Data was analysed statistically. Result: - Out of 92 subjects, 16 were suffering from gastric upset only, 03 were suffering from low back pain only and 08 were suffering from both gastric upset and low back pain. Discussion \& Conclusion: - Majority of subjects were knowing the fact that their work profile has risk of low back pain and gastric upset. But lack of knowledge of proper sitting postures and frequent working overtime made them prone to develop gastric upset and low back pain.

\section{INTRODUCTION}

A number of major morbid conditions are thought to be stress associated. Peptic ulceration is one of them. Back and spine impairments are the most common impairment among young and middle-aged people. The lifetime prevalence of low back pain is reported to be as high as $84 \%$.

Computer operators work continuously for hours in sitting posture. A number of patients come in OPD with presenting complaints of gastric upset (acidity, constipation, irregular bowel habits etc.) and/or low back pain. Many of these patients have occupational history of being computer operator.Thus we started this study.

\section{MATERIAL \& METHODS}

Study design - A descriptive cross sectional study was conducted among 92 Computer operators selected randomly from Sri Krishna Medical College \& Hospital, Newspaper offices, Banks and local markets of Muzaffarpur, Bihar. The study period was from October, 2019 to February, 2020.

Study population and Study unit - The study population was Computer operators in Muzaffarpur. The study unit was individual Computer operator.

Study tool - Data was collected through pre- designed and pre - tested questionnaire from October,2019 to February, 2020.

Statistical analysis - Data were entered and analyzed. The result was expressed in frequencies and percentage.

The respondents were informed about the objective and purpose of the study and verbal consent was obtained from each respondent during data collection.

\section{Inclusion criteria:}

- Age $<40$ years

- BMI:20-25

- Presently working as computer operator for at least 3 years on regular basis.

Exclusion criteria:

- Any history of gastric upset and/or low back pain before joining as computer operator

- Existence of any other disease

\section{RESULT}

- No. of persons suffering from:
Gastric upset only - 16

Low back pain only - 3

Both gastric upset and low back pain - 8

- Prevalence of Gastric upset $=24 / 92=26 \%$

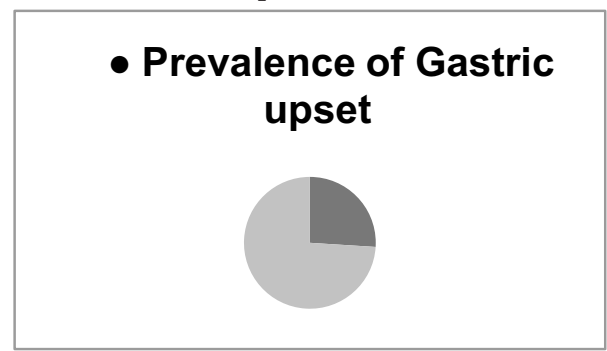

- Prevalence of Low back pain $=11 / 92=12 \%$

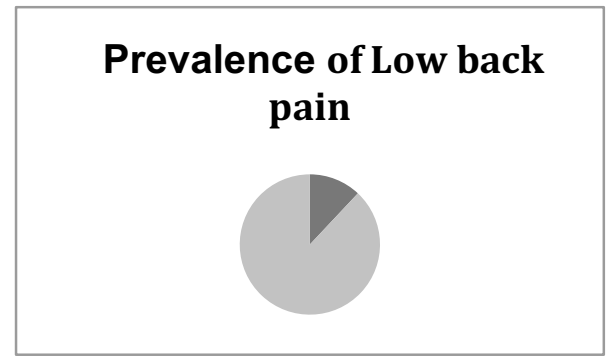

- Subjects knowing about their:

occupational risk of gastric upset-58

occupational risk of low back pain-63

- Only 8 subjects had knowledge of proper sitting posture

75 Subjects had to work overtime

\section{DISCUSSION \& CONCLUSION}

Majority of subjects were knowing the fact that their work profile has risk of low back pain and gastric upset. But lack of knowledge of proper sitting postures and frequent working overtime made them prone to develop gastric upset and low back pain. To reduce chronicity, disability, and cost, preventive measures should be explored.

\section{REFERENCES:}

1) Gunnar B J Andersson. Epidemiological features of chronic low back pain: The Lancet 354(9178), 581-585, 1999.

2) F Balague, A F Mannion, F Pellise, C Cedraschi. Non- Specific low back pain The Lancet, 2012-Elsevier.

3) R.E.M. Lees, B. R. Laundry Comparison of Reported workplace morbidity in 8-hour and 12-hour shifts in one plant:J. Soc. Occup. Med. (1989) 39,81-84.

www.worldwidejournals.com 